\title{
Notas sobre o Trypanosoma cruzi e suas características bio-ecológicas, como agente de enfermidades transmitidas por alimentos
}

\author{
Notes about of Trypanosoma cruzi and yours bio-ecology characteristcs \\ with agents of the transmission by meals
}

\author{
João Carlos Pinto Dias ${ }^{1}$
}

\begin{abstract}
RESUMO
São revistas evidências experimentais e observações de terreno que demonstram a transmissão do Trypanosoma cruzi ao homem e vários mamíferos pela via oral, que ocorre especialmente no ciclo enzoótico do parasita. Vários tipos de alimentos e veículos de carreamento do flagelado têm sido implicados nesta modalidade de transmissão, geralmente sendo os casos humanos relacionados com triatomíneos infectados nas imediações do evento. Sumariam-se as vias de penetração (mucosas da boca, esôfago, estômago e intestino) e se descrevem os principais eventos anatomopatológicos, tais como fenômenos hemorrágicos, mesenterite e hepatite intersticial. Em particular são analisados aspectos da biologia e da bioquímica do parasita, com vistas à epidemiologia da transmissão oral e às possibilidades de sua prevenção na doença de Chagas.
\end{abstract}

Palavras-chaves: Trypanosoma cruzi. Transmissão oral. Doença de Chagas. Prevenção. Epidemiologia.

\begin{abstract}
Experimental evidence and field observations concerning the oral transmission of Trypanosoma cruzi to human beings and mammalian species are reviewed, confirming its unquestionable occurrence, mainly in the enzootic cycle of the parasite. Several types of foods and carriers of the flagellate have been involved in this transmission route, where the human cases are generally related to infected triatomines and/or natural reservoirs in the proximities of the event. The penetration points of the parasite (mouth, esophagus, stomach and intestinal mucosae) are reviewed, as well as the general anatomic and pathological processes, such as hemorrhagic phenomena, mesenteritis and interstitial hepatitis. In particular, different aspects of the biology and biochemistry of the parasite are analyzed, especially in terms of its epidemiology and the possibilities of the prevention of the oral transmission of Chagas' disease.
\end{abstract}

Key-words: Trypanosoma cruzi. Oral transmission. Chagas' disease. Prevention. Epidemiology.

A transmissão do Trypanosoma cruzi por via oral (VO) tem caráter habitual no ciclo enzoótico primitivo deste parasita, através da ingestão - por mamíferos suscetíveis - de vetores e reservatórios infectados. No caso do homem, esta transmissão ocorre de maneira esporádica e circunstancial, através de alimentos contaminados com o parasita, principalmente a partir de triatomíneos ou de suas dejeções ${ }^{132560}$. Também, pode ocorrer através da ingestão de carne crua ou mal cozida de caça, ou de alimentos contaminados por urina ou secreção anal de marsupiais infectados, por acidentes em laboratório ou, mesmo, por meio de hábitos primitivos de ingestão de triatomíneos ${ }^{6192656}$. A presente nota objetiva resgatar as principais informações registradas sobre a transmissão do Trypanosoma cruzi por VO, como subsídio aos esforços para seu melhor conhecimento e prevenção, buscando-se resumir a experiência acumulada e ressaltar alguns aspectos do parasita, mais pertinentes esta modalidade de transmissão. Como pressuposto, admite-se que, no ciclo silvestre, a transmissão oral seguirá sendo uma forma habitual e freqüente de circulação do parasita, independentemente das ações de controle do vetor domiciliado e da seleção de doadores infectados nos bancos de sangue $\mathrm{e}^{175588}$.

\footnotetext{
1. Centro de Pesquisas René Rachou da Fundação Oswaldo Cruz, Belo Horizonte, MG. Endereço para correspondência: Prof. João Carlos Pinto Dias. CPqRR/FIOCRUZ. Av. Augusto de Lima 1715, 30190-002 Belo Horizonte, MG, Brasil. Tel: 5531 3349-7700

e-mail: jcpdias@cpqrr.fiocruz.br

Recebido para publicação em 15/05/06

Aceito em: 25/05/06
} 


\section{ANTECEDENTES EXPERIMENTAIS}

Possivelmente, em seus primeiros experimentos com triatomíneos infectados e sagüis, a pedido de Carlos Chagas, Oswaldo Cruz tenha sido protagonista de um evento de transmissão oral, pois colocou os insetos na jaula dos macacos e estes se infectaram, conforme 0 relato original ${ }^{15}$. Não foi ali mencionada inoculação, nem relatados sinais de porta de entrada, não se descartando a hipótese de os sagüis terem ingerido os barbeiros. No campo experimental, muito cedo Nathan-Larrier ${ }^{45}$ pode comprovar a possibilidade de transmissão oral em pequenos animais utilizando sangue com tripomastigotas, o mesmo logrando Brumpt ${ }^{10}$, Kofoid e Donat ${ }^{37}$, Cardoso $^{12}$, Dias $^{2021}$ e Marsden ${ }^{41}$. Na década de 1930, Mazza e cols relatam a infecção de ratos sadios que devoraram um roedor silvestre infectado, também registrando a infecção experimental de cães que ingeriram moscas domésticas alimentadas com fezes de triatomíneos portadores de T. $\mathrm{cruZ}^{56}$. Em 1952, Vergani infectou cães por VO, obrigando-os a comerem moscas alimentadas previamente em sangue infectado, semelhantemente fazendo Alcântara com camundongos que ingeriram Culex fatigans alimentados em animais com infecção aguda ${ }^{159}$. Em 1966, Rykman conseguiu infecções fugazes em lagartos alimentados com fezes de triatomíneos infectados, observando aumento da virulência na cepa recuperada, enquanto Davis e cols, em 1980, infectaram raposas por VO, com triturado de barbeiros portadores do parasita ${ }^{18}{ }^{48}$. Não obstante, a maior experiência coube a Carlos Diaz Ungría e cols, na Venezuela, entre as décadas de 1960 e 1980, que trabalharam com cães, cobaias e roedores, infectando-os por VO com cepas locais de T. cruzi originadas de triatomíneos naturalmente infectados ${ }^{27} 282930$. Sumariando, verificaram que leite com fezes infectadas de $R$. prolixus ingerido por cães contaminava-os facilmente, $o$ mesmo ocorrendo quando o leite era substituído por soro fisiológico. 0 período de incubação era maior que a infecção produzida por injeção (intramuscular, subcutânea ou intraperitoneal), sendo o êxito da VO geralmente dependente de inóculos grandes (100.000 formas do parasita, infectando bem mas 60.000 infectando muito mal, enquanto por injeção subcutânea poucos parasitas eram suficientes). Também, foram infectados camundongos através da mucosa do esôfago (seringa especial) e provaram a infecção intestinal através de cápsulas de gelatina para liberação intestinal, contendo fezes de triatomíneos infectados, então produzindo parasitemias muito maiores que as ocorrentes na ingestão oral de leite contaminado. Verificaram ainda que as fezes de triatomíneos infectados produziam pela VO infecções muito mais intensas que material de cultura. Realizaram experimentos com Musca domestica, Periplaneta americana e Blatella germanica alimentadas com fezes de triatomíneos infectados, logrando infecção em ratos e cães que ingeriram esses insetos, também observando transmissão a cães alimentados em moscas recolhidas de ambiente altamente infestado por triatomíneos positivos. In vitro observaram que tripomastigotas de fezes de $R$. prolixus eram parcialmente resistentes a suco gástrico de cães. Experimentalmente, também conseguiram transmitir VO outros tripanosomatídeos, como T. rangeli, T. vivax e T. evansi. No campo anatomopatológico, comprovam sinais de penetração do parasita em mucosa oral, esofagiana, gástrica e intestinal, ressaltando reação local importante (eosinofilia, infiltrados linfomonocitários e importante adenopatia satélite), com formação de mesenterite e focos primários no interstício hepático, posteriormente se dispersando o parasita pelo sistema porta ${ }^{27} 282930$.

\section{VIA ORAL EM HUMANOS}

Desde o relato de Mazza e cols ${ }^{42}$, sobre transmissão por leite materno, outras observações assinalaram casos de transmissão oral em Teutônia (RS), no Pará, na Paraíba, na Colômbia, na Argentina, no México e na Amazônia, registrando-se mais recentemente um surto em Santa Catarina $(2005)^{17233850565758}$. Um outro episódio parece ter ocorrido no Ceará, em 2006, segundo a Secretaria de Vigilância em Saúde do Ministério da Saúde (S. Santos: informação pessoal). Em acidentes de laboratório, a contaminação oral foi comprovada em técnicos que se infectaram pela ingestão de formas de cultura ou de sangue contaminado, enquanto que pelo menos um caso (na Argentina) deveu-se a ingestão comprovada de carne de caça ${ }^{1725}{ }^{56}$. A transmissão oral ao homem já foi registrada com linhagens Z1 e Z2 do parasita ${ }^{7575861}$. Revisões recentes sobre este tema encontram-se em Amato Neto e cols ${ }^{6}$, Coura $^{17}$ e Storino e Jörg ${ }^{56}$. Na grande maioria dos casos estudados, tratava-se de episódios súbitos e inesperados, ocorrendo em pequenos e limitados surtos, envolvendo entre três e dezesseis pessoas. Embora nem sempre bem caracterizado, via de regra o fato comum se prende à estada de indivíduos suscetíveis em espaços geográficos definidos e em momento restrito, implicando-se como veículo de transmissão diferentes tipos de alimento, como comida caseira, suco de cana ou açaí, sopas e caldos, carne de caça semicrua, leite etc, quase sempre se registrando a presença de vetores e/ou reservatórios infectados nas imediações do evento (ou na área de produção ou manuseio do alimento). No geral, nesses casos têm sido excluídas as formas habituais de transmissão da doença de Chagas humana (DCH), como diretamente pelo vetor, por transfusão de sangue, via congênita e por acidente em laboratório ${ }^{5258}$. Num dos pacientes da Paraíba e noutro do surto de Santa Catarina, o veículo carreador do parasita (caldo de cana) foi levado à distância e tomado fora do local de origem da contaminação, situação também aventada para vários casos supostamente contaminados com suco de açaî ${ }^{5555}$. Embora os relatos sempre dependam de constatação e estudo a posteriori ao surgimento do(s) caso(s), têm sido admitidos como principais agentes de origem do parasita os próprios triatomíneos ou suas dejeções, outros insetos contaminados a partir de triatomíneos, secreção anal ou urina de marsupiais e carne de mamíferos contaminados ${ }^{1723} 4156$. Chama a atenção a coincidência de que os episódios da Paraíba e de Santa Catarina tenham ocorrido em períodos quentes, de maior atividade biológica de triatomíneos, respectivamente 
em outubro e fevereiro ${ }^{50}$. 0 mesmo tem se verificado na Amazônia, onde cerca de $70 \%$ das 59 micro-epidemias registradas até 2005 ocorreram de agosto a dezembro ${ }^{57}$. Nessa época, a maior atividade biológica implica em maiores densidades triatomínico-tripanosômica nos ecótopos naturais e artificiais, prevalecendo os estádios alados. Há maior mobilidade dos vetores, maior hematofagismo, maior contaminação do ambiente com fezes infectadas, também sendo regra uma maior produção de casos humanos agudos pela via vetorial clássica $^{1322} 2440$. É ilustrativo um relato de Diaz Ungría, que capturou moscas domésticas em um rancho venezuelano extremamente infestado por Rhodnius prolixus infectados com T. cruzi, dando-as de comer, maceradas em leite, a um cão suscetível, que manifestou forma aguda 26 dias após ${ }^{28}$.

\section{GENERALIDADES CONCERNENTES AO PARASITA}

o Trypanosoma cruzi (Protozoa, Sarcomastigophora, Kinetoplastida, Tripanosomatidae) é um protozoário digenético e polifilético, largamente distribuído na natureza, ocorrendo sua circulação primitivamente entre insetos vetores (Triatominae, Hemíptera, Reduviidae) e mamíferos silvestres $^{9} 33$. Trata-se de um parasita muito antigo, remontando há mais de 150 milhões de anos sua presença no planeta. Dotado de grande diversidade genética, de modo geral os clones e populações estudados têm modernamente sido agrupados, mediante estudos de perfil molecular e izoenzimático, em três maiores grupos ou linhagens, denominados GI e GIII (grupos basicamente de origem silvestre, naturalmente vinculados a marsupiais) e Z2 (encontrado na DCH da América do Sul, naturalmente ligados a primatas $)^{435461}$. Sua transmissão pelo vetor dá-se de maneira contaminativa e por via posterior, o que lhe vale a inserção no grupo denominado stercoraria ${ }^{33} 35$.

\section{LOCALIZAÇÃO E EVOLUÇÃo DO PARASITA EM DIFERENTES SITUAÇÕES}

No triatomíneo detectam-se tripomastigotas, epimastigotas e massas celulares nas porções iniciais do tubo digestivo, predominando geralmente epimastigotas nas porções médias e tripomastigotas na porção distal e nos tubos de Malpighi ${ }^{20}{ }^{35}$. 0 parasita não se aloja nas glândulas salivares do inseto, mas pode encontrar-se, eventualmente, em sua cavidade geral ${ }^{92035}$. Uma vez infectado, geralmente assim permanecerá o inseto, embora eventualmente esta infecção possa ser eliminada espontaneamente em condições excepcionais, a longo prazo ${ }^{92033}$. 0 Trypanosoma cruzi também pode permanecer vivo e infectante em triatomíneos mortos e fezes do inseto deixadas no ambiente, por algumas horas ou mesmo dias, conforme as condições de temperatura, umidade e dessecamento 28335153 . No hospedeiro vertebrado, o T. cruzi pode ser encontrado em muitos e diferentes sítios, predominando na fase aguda os tripomastigotas sanguíneos e a infecção por amastigotas de órgãos e sistemas como o músculo cardíaco, músculos esqueléticos e lisos, células sanguíneas e do sistema fagocítico mononuclear (inclusive em linfonodos, baço e fígado), supra-renal (formas amastigotas e tripomastigotas), sistema nervoso, ovários e testículos, pele, tecido subcutâneo etc. Em culturas artificiais com meios enriquecidos (infusão de fígado, triptose), predominam epimastigotas, havendo tendência à diferenciação para tripomastigotas em cultivos mais velhos $^{920435}$. No vertebrado crônico, predominam as formas amastigotas em tecido muscular ou cardíaco, com duas exceções: a) em certos marsupiais (Didelphis aurita, Didelphis marsupialis, Didelphis paraguayensis etc) ocorre um ciclo especial de $T$. cruzi nas glândulas anais, similar aquele do triatomíneo, com a presença muito densa de tripo e epimastigotas, também de massas nucleadas ${ }^{19}$ e b) em indivíduos crônicos imunodeprimidos (por drogas, irradiações ou co-infecções) soe elevar-se significativamente a parasitemia (formas tripomastigotas), assim como podem ocorrer lesões dermatológicas repletas de amastigotas e formas em diferenciação ${ }^{813192639}$. Em alimentos, o parasita mostrou-se viável em experimentos com leite, sangue de mamíferos, carne crua, caldo de cana e carne de cadáver humano, por pelo menos algumas horas, à temperatura ambiente, prolongandose por dias ou semanas, em baixas temperaturas ${ }^{47} 3946$. Em caldo de cana, Soares cols ${ }^{51}$ lograram a viabilidade do parasita por até vinte e quatro horas. Trabalhando com inóculos de várias procedências (cultura, sangue e carne de reservatórios, fezes e triatomíneos macerados) nos modelos cão e camundongo, Diaz-Ungría ${ }^{27}$ verificou que os materiais mais infectantes foram aqueles procedentes do triatomíneo, lembrando-se que este autor não trabalhou com secreção de glândulas anais de marsupiais infectados. Nos estudos experimentais, a penetração do agente foi registrada na mucosa oral, esofagiana e gástrica e, principalmente, intestinal. Observam-se pequenos infiltrados, ulcerados ou não, presentes neutrófilos, eosinófilos e células mononucleadas, estas últimas podendo conter o parasita. Por analogia com as portas de

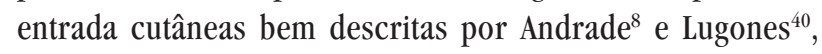
provavelmente as ulcerações da mucosa digestiva terão origem nos infiltrados inflamatórios focais ou confluentes em torno de células parasitadas, gerando intensa dilatação vascular, congestão e edema no início e que, se intensificados, redundarão em processos degenerativos, focos de necrose e sangramento. No modelo experimental, a propagação da infecção acontece por via linfática, observando-se graus variáveis de linfo-adenopatias satélites e mesenterite. Concomitantemente, ocorre difusão hematogênica, via sistema porta. Posteriormente, se encontram lesões focais no fígado, causando hepatite intersticial e, mais tarde, haverá lesões no coração e musculatura esquelética ${ }^{29}$. A evolução clínica em animais de laboratório e humanos observados, a partir de então, segue geralmente uma sequiência similar à da transmissão pelo vetor, observando-se em vários experimentos um período de incubação alguns dias maior, a depender da cepa e do inóculo ${ }^{11} 27$. 


\section{CARACTERÍSTICAS BIOQUÍMICAS, BIOLÓGICAS E FÍSICO-QUíMICAS}

É um parasita isotônico com o meio interno de mamíferos e triatomíneos vetores, sobrevivendo bem em temperaturas idealmente entre 24 e $28^{\circ} \mathrm{C}$ (inseto e culturas artificiais) e 36 a $37^{\circ} \mathrm{C}$ (mamíferos agudos ou crônicos) ${ }^{2} 3133{ }^{34}$. Neste ponto, o cozimento superficial de alimentos (carnes semicruas, por exemplo) pode ensejar a transmissão do parasita, enquanto procedimentos como a pasteurização (sucos, leite) seguramente a previnem ${ }^{3620565}$. Em plasma congelado o parasita permanece viável entre três e vinte e quatro horas. Em sangue humano conservado $\mathrm{a} 4^{\circ} \mathrm{C}$, o parasita sobrevive bem e tem capacidade infectante por uma ou duas semanas, diminuindo sensivelmente sua viabilidade na terceira semana, em especial do $18^{\circ}$ dia em diante ${ }^{14}$. Sob ultracongelamento a $70^{\circ} \mathrm{C}$ negativos o parasita conserva-se muito bem, durante anos ${ }^{934} .0 \mathrm{pH}$ ideal para o parasita é 7,2-7,3 (sangue de mamíferos, e luz do tubo digestivo dos triatomíneos) havendo morte celular em pHs francamente ácidos ou alcalinos ${ }^{2751}$.

Neste ponto, reside um dos óbices alegados para a transmissão oral da tripanossomíase americana, certamente havendo a destruição de um sem número de formas infectantes quando expostas ao meio ácido do suco gástrico. Não obstante, os experimentos com leite ou sangue contaminado e ingestão de triatomíneos e reservatórios infectados por animais suscetíveis mostram que a transmissão oral tem chances de ocorrer, penetrando os parasitas pela mucosa do esôfago, do estômago e das porções iniciais do delgado ${ }^{21} 273656$. Ilustrativamente, no recente surto de Santa Catarina de transmissão oral a seres humanos, exames endoscópicos de alguns pacientes agudos demonstraram lesões ulceradas na mucosa intestinal, com a presença de parasitas, evidenciando não somente a superação da barreira do suco gástrico, mas também a penetração e propagação do T. cruzP $P^{5}$. Por outro lado, o parasita é sensível a diversos agentes químicos presentes ou adicionados ao seu meio ambiente, como o etanol, o hipoclorito de sódio a 1\% (por uma hora), a violeta de genciana (1:4.000, por 24 horas), o psoraleno etc, podendo essas substâncias serem empregadas para eventuais propósitos de desinfecção preventiva ${ }^{23} 274$. A ação de algumas delas pode ser intensificada mediante a adição de ácido ascórbico, exposição a luz ultravioleta etc $^{132644}$. Em termos de sua nutrição, o parasita tem facilidade em sobreviver em sangue ou meios pobres de nutrientes por vários dias (duas semanas pelo menos), conforme Cerisola cols ${ }^{14}$, desde que não haja dessecamento, que não haja agressões químicas e que a temperatura não ultrapasse a faixa $\operatorname{dos} 40^{\circ} \mathrm{C}$. Tripomastigotas têm reserva energética acumulada sob forma de proteínas e lipídios, sendo incapazes de armazenar polissacarídeos, o que limita em muitas circunstâncias sua sobrevivência e capacidade de proliferação. 0 parasita retira do meio o provimento de glicose, frutose ou outros açúcares superiores, metabolizados por via glicolítica ou de pentoses ${ }^{33}{ }^{34}$. Seu metabolismo energético é processado por via oxidativa e por via anaeróbica, havendo grande consumo de $\mathrm{O}_{2}$ pelos tripomastigotas sanguíneos a $37^{\circ} \mathrm{C}$, consumo que diminui em temperaturas menores e nas formas amastigotas ${ }^{33} 34{ }^{47}$. 0 Trypanosoma cruzi é capaz de sintetizar alguns aminoácidos e bases como aspartato, alanina, glucamato e pirimidina, mas não consegue realizar a síntese de purina e de esteróis, que busca em seus hospedeiros. Mais de $40 \%$ de seu peso corresponde a proteínas e aminoácidos (principalmente alanina), estando demonstrada atividade de proteinases, envolvidas em seu crescimento, reprodução, diferenciação adesão e penetração ${ }^{33}$. No plano das características físico-químicas pertinentes à transmissão por alimentos, o $T$. cruzi é extremamente vulnerável ao dessecamento do meio em que se encontra ${ }^{2} 253$. Isto vale particularmente para as situações práticas em que fezes de triatomíneos entram em jogo no ciclo de transmissão do parasita, no sentido da contaminação de alimentos: tem sido verificado que fezes e triatomíneos secos inviabilizam o $T$. cruzi para transmissão, inclusive por via injetável, em várias investigações já realizadas $^{20} 2753$. Neste sentido, também a prática da liofilização de alimentos - a exemplo de plasma e hemoderivados - torna-se medida preventiva de alta eficácia sobre a transmissão oral de T. cruzỉ. Já a possibilidade de utilização de radiações ionizantes, como forma de esterilizar o meio e prevenir a transmissão oral deste parasita, um estudo experimental mostrou a pouca efetividade do emprego de raios gama sobre sangue infectado (nenhuma atividade até 5.000 RADS), o que desestimula novas tentativas 5 . No plano biológico, pesquisa recente em camundongos verificou a ocorrência de transmissão por via oral com as cepas Colombiana (Z1) e Peruana (Z2b) ${ }^{11}$. Comparando com animais inoculados intraperitonealmente, nos casos de transmissão oral, a parasitemia foi mais tardia e mais discreta. Já a patogenicidade e a intensidade do parasitismo tissular foram muito menores nos animais inoculados por via intragástrica com a cepa Peruana, em relação à via intraperitoneal e à cepa Colombiana ${ }^{11}$. Complementarmente, Cortez cols comprovaram em camundongos, os diferentes graus de infectividade da mucosa gástrica e intestinal por diferentes cepas de T. cruzi, correlacionando esta infectividade com o nível de expressão da molécula gp90, que inversamente regula a penetração do parasita nas células do hospedeiro ${ }^{16}$. Outros trabalhos procuram interpretar a resistência do parasita à digestão ácido-proteásica ao nível gástrico pela presença, em sua superfície, de moléculas protetoras (mucin-like gp 35/50) ${ }^{49}$.

\section{ASPECTOS PRÁTICOS QUANTO À PREVENÇÃO DA TRANSMISSÃO ORAL DA DOENÇA DE CHAGAS}

À raiz da experiência acumulada e aqui sumariada, vários corolários e desdobramentos práticos no que toca ao parasita podem ser aventados, de forma pontual, como fecho da presente nota:

- A ocorrência de transmissão do T. cruzi por meio de alimentos é fato comprovado em diferentes modelos experimentais e em observações de seres humanos.

- Evidências experimentais sugerem que a transmissão oral pode ocorrer a partir de formas tripomastigotas, 
epimastigotas e, provavelmente, de amastigotas e massas celulares, originárias de mamíferos ou vetores contaminados, assim como, acidentalmente, de cultivos artificiais do parasita.

- No domínio dos grandes grupos ou linhagens do T. cruzi, tem sido observada transmissão oral em seres humanos tanto por Z1 e Z3 (Amazônia e Paraíba) como por Z2 (Santa Catarina $)^{757}$. Não obstante, e conforme evidências experimentais, certamente há diversidade de patogenicidade, histiotropismo e morbi-mortalidade, conforme a cepa transmitida e o inóculo em questão.

- A transmissão oral por alimentos da doença humana, tanto pode depender de ingestão de material contaminado com triatomíneos infectados ou suas fezes (maiores probabilidades), como pela ingestão de carne crua ou mal cozida de mamíferos portadores do parasita (situações muito mais raras), ou, ainda, pelas secreções de alguns mamíferos infectados, particularmente marsupiais ${ }^{419}{ }^{25}$.

- Fezes de triatomíneos podem permanecer algumas horas infectantes em ambiente com elevada umidade, assim podendo contaminar tanto alimentos como patas e aparelho bucal de carreadores secundários, como moscas e baratas ${ }^{285253}$.

- Em alimentos como o leite ou caldo de cana, à temperatura ambiente, o parasita pode manter-se viável por vinte e quatro horas ou mais, em estudos experimentais $^{27} 4652$

- Embora, o suco gástrico dos vertebrados superiores tenha a capacidade de destruir muitos parasitas, uma certa proporção dos mesmos é capaz de evadir-se desta ação, mediante mecanismos químicos de proteção externa, o que possibilita sua penetração através da mucosa intestinal.

- Resfriamento ou congelamento de alimentos não previne a transmissão oral pelo T. cruzi , mas a cocção acima de $45^{\circ} \mathrm{C}$, a pasteurização e a liofilização o fazem.

- A prevenção por irradiação de alimentos através de raios gama mostra-se sem eficácia, na prática.

- Uma série de compostos químicos teoricamente pode eliminar o parasita de alimentos suspeitos, assunto praticamente não explorado e que merece investigação, particularmente para situações pontuais (fabricação de suco de açaí, por exemplo).

- A ultrafiltragem para reter o T. cruzi é teoricamente possível, mas mostrou-se sem nenhuma praticidade na prevenção da transmissão transfusional ${ }^{44}$.

- Os casos humanos descritos e os estudos experimentais indicam um período de incubação similar ao da contaminação usual pelo inseto vetor, provavelmente um pouco aumentado, a depender de cepa e do inóculo.

- Na transmissão da esquizotripanose por via digestiva, fenômenos de enterite, abdome agudo, sangramento fecal, choque, hepatite focal e elevação de aminotransferases (TGP, TGO) podem ocorrer e têm significação prognóstica variada, devendo ser rotineiramente pesquisados e monitorados pelo clínico.

\section{REFERÊNCIAS BIBLIOGRÁFICAS}

1. Alcântara FG. Transmissão experimental do T. cruzi a camundongos pelo pernilongo Culex fatigans. O Hospital 63: 19-23, 1960.

2. Alvarenga NJ, Marsden PD. Estudos sobre a persistência da infectividade do Trypanosoma cruzi. I. Efeito da temperatura sobre a infectividade de flagelados da amostra peruana de $T$. cruzi obtidas de fezes de triatomíneos. Revista da Sociedade Brasileira de Medicina Tropical 9: 283-287, 1975.

3. Amato Neto V, Leonhard H, Souza HB. Liofilização de plasma: medida capaz de evitar a transmissão da doença de Chagas em bancos de sangue. Revista do Instituto de Medicina Tropical de São Paulo 8: 122-124, 1960.

4. Amato Neto V, Lopes MH, Umezawa ES, Ruocco RMSA, Dias JCP. Outras formas de transmissão do Trypanosoma cruzi. Revista de Patologia Tropical 29 (supl):115-130, 2000.

5. Amato Neto V, Pasternak J, Matsubara I, Hammershalk M, Caragnani FI Tentativas de uso de raios gama para prevenir a infecção transfusional pelo Trypanosoma cruzi. Revista da Sociedade Brasileira de Medicina Tropical 29: 613-614, 1996.

6. Amato Neto V, Santos RR, Gioia I. Estudo experimental sobre o congelamento do plasma e implicações referentes à transmissão da doença de Chagas em serviços de hemoterapia. Revista da Sociedade Brasileira de Medicina Tropical 9: 129-132, 1975.

7. Andrade SG, Magalhães JB, Sobral KSC, Rosado AP, Oliveira FLS Caracterização de cepas do Trypanosoma cruzi isoladas durante o surto agudo de doença de Chagas por transmissão oral, em Santa Catarina, Brasil. XLII Congresso Teresina, PI, março de 2006. Revista da Sociedade Brasileira de Medicina Tropical 39 (supl I):7, 2006.

8. Andrade ZA. Patologia. In: Brener Z, Andrade ZA (orgs) Trypanosoma cruzi e doença de Chagas. Editora Guanabara Koogan, Rio de Janeiro, p.198-246, 1979.

9. Brener Z. 0 parasito: relações hospedeiro-parasito. In: Brener Z, Andrade ZA (orgs) Trypanosoma cruzi e doença de Chagas. Editora Guanabara Koogan, Rio de Janeiro, p. 1-41, 1979.

10. Brumpt E. Precis de Parasitologíe, Paris, Masson, Tome 1, 1931

11. Camandaroba EL, Pinheiro Lima CM, Andrade SG. Oral transmission of Chagas Disease: importance of Trypanosoma cruzi biodeme in the intragastric experimental infection. Revista do Instituto de Medicina Tropical de São Paulo 44: 97-103, 2002

12. Cardoso FA. Sur le mechanisme de la transmission de la maladie de Chagas Annales de Parasitologíe Humaine 16: 341-349, 1933.

13. Carlier Y, Dias JCP, Luquetti A0, Hontebevrie M, Torrico F, Truyens C. Trypanosomiase américaine ou maladie de Chagas. Enciclopédie MédicoChirurgicale 8: 505-A20, 2002.

14. Cerisola JA, Rabinovich AL, Alvarez M, Corleto MA, Pruneda J. Enfermedad de Chagas y la transfusión de sangre. Boletín de la Oficina Sanitária Panamericana 73: 203-221,1972.

15. Chagas CRJ. Nova tripanozomiaze humana. Estudos sobre a morfologia e o ciclo evolutivo do Schizotrypanum cruzi, n. gen. N. esp, ajente etiológico de nova entidade mórbida do homem. Memórias do Instituto Oswaldo Cruz 1: 159-218, 1909.

16. Cortez M, Silva MR, Neira I, Ferreira D, Sasso GRS, Luquetti A0, Rassi A, Yoshida N. Trypanosoma cruzi surface molecule gp90 down regulates invasion of gastric mucosal epithelium in orally infected mice. Microbes and Infection 8: 36-44, 2006.

17. Coura JR. Mecanismo de transmissão da infecção chagásica ao homem por via oral. Revista da Sociedade Brasileira de Medicina Tropical 30 (supl 1): 45-47, 1997.

18. Davis DS, Russel L, Adams LJ. An experimental infection of Trypanosoma cruzi in stripped skunks (Mephitis mephitis). Journal of Wildlife Diseases 16: 403-408, 1980 .

19. Deane MP, Lenzi HL, Jansen AM. Trypanosoma cruzi: vertebrate and invertebrate cycles in the same mammal host, the opossum. Memórias do Instituto Oswaldo Cruz 79: 513-515, 1984.

20. Dias E. Estudos sobre o Schizotrypanum cruzi. Tese de Doutoramento. Faculdade Nacional de Medicina, Rio de Janeiro, 1933 
21. Dias E. Transmissão do Schizotrypanum cruzi entre vertebrados, por via digestiva. Brasil Médico 54: 775-776, 1940.

22. Dias E. Informações acerca de 300 casos de doença de Chagas com período inicial conhecido, fichados no Centro de Estudos de Bambuí. 0 Hospital 47: 647-653, 1955.

23. Dias JCP. Mecanismos de transmissão. In: Brener Z, Andrade ZA (orgs) Trypanosoma cruzi e doença de Chagas. Editora Guanabara Koogan, Rio de Janeiro, p. 152-174, 1979.

24. Dias JCP. Doença de Chagas em Bambuí, Minas Gerais, Brasil. Estudo clínico-epidemiológico a partir da fase aguda, entre 1940 e 1982. Tese. Faculdade de Medicina da Universidade Federal de Minas Gerais, Belo Horizonte, 1982

25. Dias JCP. Epidemiologia. In: Brener Z, Andrade ZA, Barral Neto M (orgs) Trypanosoma cruzi e doença de Chagas. Editora Guanabara Koogan, Rio de Janeiro, p. 48-74, 2000.

26. Dias JCP, Macedo VO. Doença de Chagas. In: Coura JR (org) Dinâmica das Doenças Infecciosas e Parasitárias. Editora Guanabara Koogan, Rio de Janeiro, p. 557-593, 2005.

27. Diaz-Ungría C. Estudio experimental del Trypanosoma cruzi en el perro y otros vertebrados. El problema de la transmisión. Kasmera (Venezuela) 3:73-88, 1968.

28. Diaz-Ungría C. La mosca doméstica como transmisora del Tripanosoma cruzi. Revista de la Universidad de Zulia 44: 114-119, 1969.

29. Diaz-Ungría C, Bracho JS. Camino que sigue el Tripanosoma cruzi en perros infectados por la vía bucal: nuevos estudios. Revista Veterinaria Venezolana 29: 271-278, 1970 .

30. Diaz-Ungría C, Zeuss M. Transmisión del Trypanosoma evansi a partir de heces de animales infectados por vía bucal. Revista veterinaria venezolana 30: 187-193, 1971.

31. Dvorak J. T. cruzi-vertebrate cell interaction. In: New approaches in American Trypanosomiasis Research. Pan American Sanitary Bureau Scientific Publication; no. 318. Washington, p. 109-120, 1976.

32. Garcia EL, Vieira E, Gomes JEPL, Gonçalves AM. Molecular biology of the interaction Tripanosoma cruzi invertebrate host. Memórias do Instituto Oswaldo Cruz 79 (supl): 33-37, 1984.

33. Gonzáles Capa S, Durante EI. Agente etiológico: Trypanosoma cruzi. In: Storino R, Milei J (orgs) Enfermedad de Chagas. Buenos Aires, Doyma Argentina, p.31-40, 1994.

34. Gutteridge WE. Biochemistry of Trypanosoma cruzi. In: New approaches in American Trypanosomiasis Research. Pan American Sanitary Bureau Scientific. Publication 318. Washington, p. 135-140, 1976.

35. Hoare C. The Trypanosomes of Mammals. $2^{\text {nd }}$ edição, Blackwell Scientific Publication, Oxford, 1972.

36. Hoft DF, Farrar PL, Kratz-Owen K, Schaffer D. Gastric invasion by Trypanosoma cruzi and induction of protective mucosal immune responses. Infection Immunology 64: 3800-3810, 1996.

37. Kofoid CA, Donat F. Experimental infection with Trypanosoma cruzi from the intestine of cone-nose bug Triatoma protracta. Procedings of Society of Experimental Biology 30: 489-491, 1933.

38. Lainson R, Shaw JJ, Naif RD. Chagas' disease in the Amazon Basin: speculation on transmission per os. Revista do Instituto de Medicina Tropical de São Paulo 22: 62-67, 1980.

39. Lopes ER, Chapadeiro E. Pathogenesis of American Trypanosomiasis. In: Maudlin I, Holmes P, Miles MA (eds) The Trypanosomes. CABI International, London, p. 303-330, 2004.

40. Lugones H, Ledesma O, Storino RA, Marteleur A, Meneclier CR, Barbieri G. Chagas agudo. In: Storino R, Milei J (orgs) Enfermedad de Chagas. Buenos Aires, Doyma Argentina, p. 209-234, 1994.

41. Marsden PD. Trypanosoma cruzi infection in CFI mice. II: infection induced by different routes. Annals of Tropical Medicine and Parasitology 61: 62-67, 1967.

42. Mazza S, Montana A, Benitez C, Janzi E. Transmisión del Schizotripanum cruzi al niño por leche de madre con enfermedad de Chagas. MEPRA 28: 41-49, 1936
43. Miles MA. The agent. In: Gilles HM (org) Protozoal Diseases. Arnold Editora, London, p. 313-322, 1999.

44. Moraes-Souza H, Ramirez LE, Bordin JO. Doença de Chagas transfusional: medidas de controle. In: Dias JCP, Coura JR (orgs) Clínica e Terapêutica da Doença de Chagas: uma abordagem prática para 0 clínico geral. Editora da Fundação Oswaldo Cruz, Rio de Janeiro, p. 411-428, 1997.

45. Nattan-Larrier L. Infections à Trypanosomes et voies de penetrations des virus. Bulletin de la Societé de Pathologie Exotique 14: 537-542, 1921.

46. Pinto PLS, Amato Neto V, Nascimento SAB, Souza HBWT, Myamoto A, Moreira AAB, Braz Lima A. Observações sobre a viabilidade do Trypanosoma cruzi no caldo de cana. Revista do Instituto de Medicina Tropical de São Paulo 32: 325-327, 1990.

47. Rey L. Parasitologia. $2^{a}$ edição. Editora Guanabara Koogan, Rio de Janeiro, 1991

48. Rykman C. Epizoology of Trypanosoma cruzi in southwestern North America. Entomology of Honolulu, 2: 87-91, 1966.

49. Schenkman S, Ferguson N, Heise ML, Almeida RAC, Mortara RA, Yoshida N. Mucin-like glycoproteins linked to the membrane by glycosiylphosphatidy-linositol anchor the major acceptors of sialic acid in a reaction catalysed by trans-sialidase in metacyclic forms of Trypanosoma cruzi. Molecular Biochemstry and Parasitology 59: 293-304, 1993.

50. Shikanai-Yasuda MA, Marcondes CB, Guedes LA, Siqueira GS, Barone AA, Dias JCP, Amato Neto V, Tolezano JE, Peres BA, Arruda Jr ER, Lopes MA, Shiroma M, Chapadeiro E. Possible oral transmission of acute Chagas' disease in Brazil. Revista do Instituto de Medicina Tropical de São Paulo 33: 355-361, 1991.

51. Soares VA, Dias JCP, Marsden PD. Sobrevivência do Trypanosoma cruzi em caldo de cana: resultados preliminares. Revista da Sociedade Brasileira de Medicina Tropical 20 (supl 2): 38, 1987.

52. Soares VA, Marsden PD. Persistência da infectividade do T. cruzi em barbeiros mortos. Revista do Intituto de Medicina Tropical de São Paulo 20: 241-242, 1978.

53. Soares VA, Marsden PD, Johnson C. Efeitos da dessecação das fezes de triatomíneos na sobrevivência de formas metacíclicas de Trypanosoma cruzi. Revista da Sociedade Brasileira de Medicina Tropical 19: 233-238, 1986.

54. Souza W. O parasito e sua interação com os hospedeiros. In: Brener Z, Andrade ZA, Barral Neto M (orgs) Trypanosoma cruzi e doença de Chagas. Editora Guanabara Koogan, Rio de Janeiro, p.88-126, 2000.

55. Steindel M, Dias JCP, Romanha AJ. Doença de Chagas: mal que ainda preocupa. Ciência Hoje 37: 32-38, 2005.

56. Storino R, Jorg ME. Vias de infección y aspectos clínicos. In: Storino R, Milei J (orgs) Enfermedad de Chagas. Buenos Aires, Doyma Argentina, p. 132-141, 1994.

57. Valente SAS. Epidemiologia da transmissão oral da doença de Chagas. Exposição na Mesa Redonda Situação atual da doença de Chagas na Amazônia. XLI Congresso da Sociedade Brasileira de Medicina Tropical, Forianópolis, março de 2005.

58. Valente SAS, Valente VC, Frahia-Neto H. Considerations on the epidemiology and transmission of Chagas Disease in the Brazilian Amazon. Memórias do Instituto Oswaldo Cruz 94 (supl 1): 395-398, 1999.

59. Vergani F. Estudio sobre la vección de tripanosomas por medio de dipteros no vulnerables. Boletín del Instituto de Investigaciones Veterinarias 4: 657 $661,1952$.

60. World Health Organization. Control of Chagas Disease. Geneva. WHO Technical Report Series 905, 2002.

61. Zingales B, Stolf BS, Souto RP, Fernandez O, Briones MRS. Epidemiology, biochemstry and evolution of Trypanosoma cruzi lineages base don ribosomal RNA sequences. Memórias do Instituto Oswaldo Cruz 94 (supl 1): 159-164, 1999 